\title{
Interaction of GCAP1 with retinal guanylyl cyclase and calcium: sensitivity to fatty acylation
}

\author{
Igor V. Peshenko, Elena V. Olshevskaya and Alexander M. Dizhoor*
}

Department of Basic Science and Pennsylvania College of Optometry, Salus University, Elkins Park, PA, USA

\section{Edited by:}

Michael R. Kreutz, Leibniz-Institute

for Neurobiology, Germany

\section{Reviewed by:}

Carlo Sala, CNR Institute of

Neuroscience, Italy

Karl-Wilhelm Koch, Carl von

Ossietzky University Oldenburg,

Germany

\section{${ }^{*}$ Correspondence:}

Alexander M. Dizhoor, Department of Basic Science and Pennsylvania

College of Optometry, Salus

University, 8360 Old York Road,

Elkins Park, PA 19027, USA.

e-mail: adizhoor@salus.edu
Guanylyl cyclase activating proteins (GCAPs) are calcium/magnesium binding proteins within neuronal calcium sensor proteins group (NCS) of the EF-hand proteins superfamily. GCAPs activate retinal guanylyl cyclase (RetGC) in vertebrate photoreceptors in response to light-dependent fall of the intracellular free $\mathrm{Ca}^{2+}$ concentrations. GCAPs consist of four EF-hand domains and contain N-terminal fatty acylated glycine, which in GCAP1 is required for the normal activation of RetGC. We analyzed the effects of a substitution prohibiting $\mathrm{N}$-myristoylation (Gly2 $\rightarrow$ Ala) on the ability of the recombinant GCAP1 to co-localize with its target enzyme when heterologously expressed in HEK293 cells. We also compared $\mathrm{Ca}^{2+}$ binding and RetGC-activating properties of the purified non-acylated G2A mutant and C14:0 acylated GCAP1 in vitro. The G2A GCAP1 expressed with a C-terminal GFP tag was able to co-localize with the cyclase, albeit less efficiently than the wild type, but much less effectively stimulated cyclase activity in vitro. $\mathrm{Ca}^{2+}$ binding isotherm of the G2A GCAP1 was slightly shifted toward higher free $\mathrm{Ca}^{2+}$ concentrations and so was $\mathrm{Ca}^{2+}$ sensitivity of RetGC reconstituted with the G2A mutant. At the same time, myristoylation had little effect on the high-affinity $\mathrm{Ca}^{2+}{ }^{+}$-binding in the EF-hand proximal to the myristoyl residue in three-dimensional GCAP1 structure. These data indicate that the N-terminal fatty acyl group may alter the activity of EF-hands in the distal portion of the GCAP1 molecule via presently unknown intramolecular mechanism.

Keywords: photoreceptors, calcium, guanylyl cyclase, myristoylation

\section{INTRODUCTION}

Retinal guanylyl cyclase activating proteins (GCAPs) form a subfamily within the neuronal calcium sensor (NCS) proteins group of the EF-hand superfamily (reviewed in: Burgoyne, 2007). The GCAPs are closely related to neurocalcin, hippocalcin, recoverin, and other NCS proteins and share a number of typical features for the group: they consist of two pairs of calmodulin-type EFhands (Ames et al., 1999; Stephen et al., 2006, 2007), of which the $\mathrm{N}$-terminal EF-hand 1 does not bind divalent cation, and are modified at the $\mathrm{N}$-terminus by fatty acyl group (Figure 1A). The modification is commonly referred to as myristoylation, although in mammalian retinal proteins, the $\mathrm{N}$-terminal Gly group can be fatty acylated by one of four different $\mathrm{C} 14$ and $\mathrm{C} 12$ derivatives (Dizhoor et al., 1992; Johnson et al., 1994), all of which can be found in GCAP (Palczewski et al., 1994).

Among the NCS proteins, GCAPs arguably have the most clearly understood physiological function. The GCAPs regulate activity of retinal membrane guanylyl cyclase (RetGC) in photoreceptors in a $\mathrm{Ca}^{2+}$-sensitive manner (Koch and Stryer, 1988; Dizhoor et al., 1994, 1995; Gorczyca et al., 1994) and thus critically expedite recovery and light adaptation of rods and cones (Mendez et al., 2001; Burns et al., 2002; Sakurai

\footnotetext{
Abbreviations: EGTA, ethylene glycol-bis(2-aminoethylether)-N,N, $\mathrm{N}^{\prime}, \mathrm{N}^{\prime}$ tetraacetic acid; GCAP, guanylyl cyclase activating protein; RetGC, retinal membrane guanylyl cyclase; GFP, green fluorescent protein; NCS proteins, neuronal calcium binding proteins.
}

et al., 2011). Rods and cones maintain partially depolarized state in the dark by opening a fraction of cGMP-gated channels in the outer segment, thus allowing influx of $\mathrm{Na}^{+}$and $\mathrm{Ca}^{2+}$. In the light, when bleached photopigment activates phototransduction cascade, cGMP becomes rapidly depleted by light-activated phosphodiesterase and the cGMP-gated channels become closed, thus causing hyperpolarization of the membrane-the first cellular step in visual signal detection (reviewed in: Fu and Yau, 2007). Photoreceptors can quickly recover from excitation and adapt to background illumination by re-opening cGMP-gated channels, and GCAPs control one of the key biochemical pathways expediting the recovery and light adaptation. In response to illumination, GCAPs activate cGMP re-synthesis via negative calcium feedback mechanism that trails the excitation state of the photoreceptor (reviewed in: Pugh et al., 1997, 1999). $\mathrm{Ca}^{2+}$ is constantly extruded from the outer segment via $\mathrm{Na} / \mathrm{Ca}$, $\mathrm{K}$-exchanger, in the dark, when several percent of the cGMP-gated channels are open at any given time, $\mathrm{Ca}^{2+}$ can re-enter the outer segment through the open channels and accumulates in the cytoplasm at submicromolar concentrations. In mouse rods, the measured steadystate concentrations in the dark approach $250 \mathrm{~nm}$ (as high as $410-560 \mathrm{~nm}$ free $\mathrm{Ca}^{2+}$ were reported in lower vertebrates) and rapidly fall nearly 10 -fold in the light, when the cGMPgated channels are shut down (Gray-Keller and Detwiler, 1994; Sampath et al., 1999; Woodruff et al., 2002). Therefore, GCAPs bind $\mathrm{Ca}^{2+}$ and maintain their inhibitory conformation that 

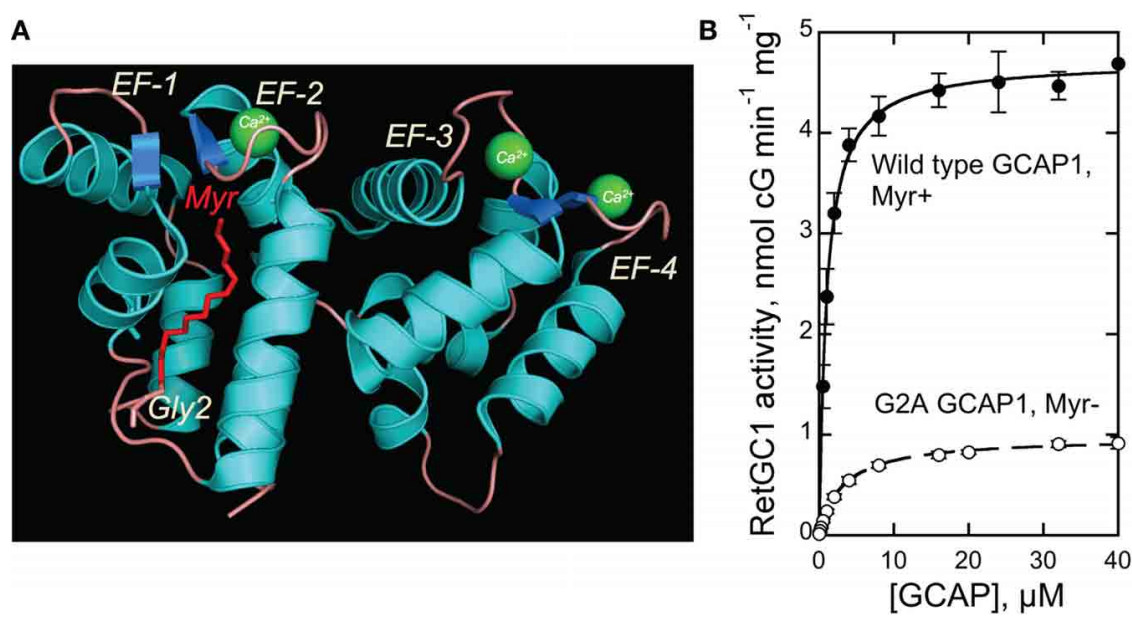

FIGURE 1 | (A) Structure of myristoylated GCAP1 [Stephen et al. (2007)]. Myristoyl residue buried inside the EF-1/EF-2 pair of EF-hands is shown in red. (B) Dose-dependence of recombinant RetGC1 activation by myristoylated and G2A GCAP1 (mean \pm SD). For details of the assay-see Materials and Methods.

decelerates RetGC in the dark (Dizhoor and Hurley, 1996; Dizhoor et al., 1998). $\mathrm{Mg}^{2+}$ can actively compete with $\mathrm{Ca}^{2+}$ binding in EF-hand domains of GCAPs (Peshenko and Dizhoor, 2004), and at the low free $\mathrm{Ca}^{2+}$ levels in the light it converts GCAPs into $\mathrm{Mg}^{2+}$-bound, RetGC activator state. This stimulates cGMP synthesis and, therefore, allows the rod to timely re-open the cGMP-gated channels and recover from the hyperpolarization state. Following the completion of recovery, $\mathrm{Ca}^{2+}$ returned through the re-opened cGMP-gated channels converts GCAPs back to their $\mathrm{Ca}^{2+}$-bound inhibitory form, thus completing the light-driven functional cycle of GCAP (reviewed in: Dizhoor et al., 2010).

GCAPs exist in several isoforms (Imanishi et al., 2004), of which GCAP1 (Gorczyca et al., 1994; Palczewski et al., 1994) and GCAP2 (Dizhoor et al., 1994, 1995) are ubiquitous among all tested vertebrate species. They regulate RetGC with distinctly different sensitivities to $\mathrm{Ca}^{2+}$ (Hwang and Koch, 2002; Hwang et al., 2003; Peshenko et al., 2004, 2011) and, therefore, sequentially activate RetGC at different phases of rod photoresponse (Makino et al., 2008). The two GCAPs also differ in their requirement of the $\mathrm{N}$-fatty acylation for their function. While $\mathrm{N}$-myristoylation has relatively modest impact on the regulatory activity of GCAP2 in vitro (Olshevskaya et al., 1997), it is much more critically needed for the activity of GCAP1 (Otto-Bruc et al., 1997; Hwang and Koch, 2002). The best-known $\mathrm{Ca}^{2+}$-dependent conformational change described for NCS proteins is a "calciummyristoyl switch"- $\mathrm{Ca}^{2+}$-dependent release of the myristoylated $\mathrm{N}$-terminus from the cavity created by alpha-helical structures of EF-hands 1 and 2 (Zozulya and Stryer, 1992; Dizhoor et al., 1993; Ames et al., 1995, 1997; Lim et al., 2011). In contrast, NMR data argue that myristoyl chain does not undergo $\mathrm{Ca}^{2+}$-myristoyl switch in GCAP1 and GCAP2 (Hughes et al., 1998; Lim et al., 2009), and it remains buried inside the protein in the X-ray crystal structure of GCAP1 (Stephen et al., 2007) (Figure 1A). In this study, we addressed functional effects of $\mathrm{N}$-fatty acylation in bovine GCAP1 on its interaction with the target enzyme and the ability to "sense" $\mathrm{Ca}^{2+}$.

\section{MATERIALS AND METHODS MUTAGENESIS}

Mutations were introduced in bovine GCAP1 cDNA by "splicing by overlap extension" technique using PCR reactions catalyzed by high-fidelity Phusion Flash polymerase (Finnzymes). The resultant products were ligated into the NcoI/BamHI sites of pET11d (Novagene) vector, sequenced, and transformed into expressing cell lines as described previously in detail (Peshenko and Dizhoor, 2006). RetGC1 tagged by mOrange was constructed by inserting mOrange (Clontech) cDNA into a modified human RetGC1 cDNA-harboring pRCCMV plasmid (Laura et al., 1996) as follows. The XhoI-XhoI fragment of the vector was excised by XhoI digest and self-ligation, then the coding region for the extracellular domain of RetGC1 was modified by ligating a linker fragment into the HindIII/BsteII sites to introduce two new restriction sites, NheI and AgeI beginning after 33 base pairs downstream from the leader peptide-coding fragment. The mOrange cDNA, PCR-amplified with the NheI and AgeI sites at the $5^{\prime}$ - and $3^{\prime}$ end, respectively, was ligated into the corresponding restriction sites of the modified pRetGC1-RCCMV plasmid. The resultant construct encoded 238 a.a. mOrange protein sequence downstream from the 51 a.a. leader peptide, replacing a short fragment, Ala63-Phe68, of the RetGC1 extracellular domain.

\section{GCAP1 PURIFICATION}

Myristoylated bovine D6S GCAP1 was produced in BLR(DE3) E. coli strains harboring yeast N-myristoyl transferase (NMT), extracted from inclusion bodies and purified to $\sim 95 \%$ electrophoretic purity using $\mathrm{Ca}^{2+}$ precipitation, butyl-Sepharose chromatography, and high-resolution gel-filtration as previously described in detail (Peshenko and Dizhoor, 2006). The expressing strain for non-myristoylated G2A GCAP1 lacked the NMT plasmid.

\section{$\mathrm{Ca}^{2+} /$ EGTA BUFFERS}

$\mathrm{Ca}^{2+} /$ EGTA mixtures were prepared according to Tsien and Pozzan (1989), protocol and verified with $\mathrm{Ca}^{2+}$ fluorescent 
indicator dyes as described previously (Peshenko and Dizhoor, 2006). The free metal concentrations in assays containg $2 \mathrm{mM}$ $\mathrm{Ca}^{2+} /$ EGTA buffer were calculated using Bound and Determined and MaxChelator software with proper corrections for $\mathrm{pH}$, salt and nucleotide concentrations, and temperature.

\section{$\mathrm{Ca}^{2+}$ BINDING ASSAY \\ $\mathrm{Ca}^{2+}$ binding isotherms were obtained using previously described modification of a fluorescent indicator dye titration approach (Peshenko and Dizhoor, 2006). Briefly, each GCAP1 was diluted from $300-350 \mu \mathrm{m}$ stock solution to $20-40 \mu \mathrm{m}$ final concen- tration in $0.6 \mathrm{ml}$ of $100 \mathrm{~mm} \mathrm{MOPS/KOH}(\mathrm{pH} 7.2), 40 \mathrm{mM}$ $\mathrm{KCl}, 1 \mathrm{mM}$ dithiothreitol, and $0.5 \mu \mathrm{M}$ BAPTA 2 (Molecular Probes/Invitrogen). The mixture assembled in a plastic cuvette was titrated at $23^{\circ} \mathrm{C}$ with addition of $3 \mu \mathrm{l}$ aliquots of calibrated $\mathrm{CaCl}_{2}$ solution.}

\section{GUANYLYL CYLASE ASSAYS}

RetGC activity was assayed as described previously (Peshenko and Dizhoor, 2007; Peshenko et al., 2011). Briefly, the assay mixture $(25 \mu \mathrm{l})$ incubated at $30^{\circ} \mathrm{C}$ contained $30 \mathrm{mM}$ MOPS- $\mathrm{KOH}$ (pH 7.2), 60 mM KCl, 4 mM NaCl, 1mM DTT, 2 mM Ca ${ }^{2+} /$ EGTA buffer, $1 \mathrm{mM}$ free $\mathrm{Mg}^{2+}, 0.3 \mathrm{mM}$ ATP, $4 \mathrm{mM}$ cGMP, $10 \mathrm{mM}$ creatine phosphate, 0.5 unit of creatine phosphokinase, $1 \mathrm{mM}$ GTP, $1 \mu \mathrm{Ci}$ of $\left[\alpha^{-32} \mathrm{P}\right] \mathrm{GTP}, 0.1 \mu \mathrm{Ci}$ of $\left[8^{3} \mathrm{H}\right] \mathrm{cGMP}$ (Perkin Elmer), PDE6 inhibitors zaprinast, and dipyridamole. The resultant $\left[{ }^{32} \mathrm{P}\right] \mathrm{cGMP}$ product and the $\left[{ }^{3} \mathrm{H}\right] \mathrm{cGMP}$ internal standard was analyzed by TLC using fluorescently backed polyethyleneimine cellulose plates (Merck) developed in $0.2 \mathrm{M} \mathrm{LiCl}$.

\section{EXPRESSION OF RetGC1 IN HEK293 CELLS}

HEK 293 cells grown at $37^{\circ} \mathrm{C}, 5 \% \mathrm{CO}_{2}$, in high-glucose Dulbecco's modified Eagle medium (DMEM, Invitrogen) supplemented with $10 \%$ fetal bovine serum (Invitrogen) were transfected using the $\mathrm{Ca}^{2+}$-phosphate method (a Promega Profection protocol) with $40 \mu \mathrm{g}$ per $100 \mu \mathrm{m}$ culture dish of pRCCMV plasmid coding for human RetGC1, and the membranes containing recombinant RetGC1 were isolated as previously described in detail (Peshenko et al., 2004).

\section{CO-EXPRESSION OF RetGC1 AND GCAP1 IN HEK 293 CELLS AND CONFOCAL LASER SCANNING MICROSCOPY}

Fluorescently tagged GCAP1 was co-expressed in HEK293 cells with human RetGC1 as previously described (Peshenko et al., 2008, 2010). Cells grown in $2 \mathrm{~cm}^{2}$ cover slip chambers were typically transfected with a mixture of $3 \mu \mathrm{g}$ pRCCMV plasmid harboring RetGC1 cDNA and $0.02 \mu \mathrm{g}$ of the GCAP1-GFP pQBI25fN3 plasmid. In $24 \mathrm{~h}$ the cells were either viewed directly or fixed with freshly prepared $4 \%$ paraformaldehyde at room temperature for subsequent immunostaining. The images were collected using FV1000 Spectral laser confocal system and analyzed using Olympus FluoView FV10-ASW software as previously described (Peshenko et al., 2008).

\section{RESULTS AND DISCUSSION}

We tested the RetGC1-stimulating activity of a nonmyristoylated recombinant bovine G2A GCAP1 produced in
E. coli in comparison with the myristoylated GCAP1 (Figure 1B). Both myristoylated and non-myristoylated protein were produced using D6S variant of GCAP1, required for high-efficiency myristoylation in BLR(DE3) E. coli strain harboring yeast myristoyl transferase (Dizhoor et al., 1998; Krylov et al., 1999). To ensure the complete lack of myristoylation, the N-terminal Gly2 (Figure 1A) replaced with Ala prevents recognition of GCAP1 by NMT (Otto-Bruc et al., 1997). Molecular masses of the purified non-myristoylated G2A GCAP1 and myristoylated GCAP1 verified by ESI-QTOF mass-spectrometry matched, within one mass unit accuracy, their predicted molecular masses (23,365 and 23,561 , respectively). Consistently with the previously reported observations using native photoreceptor membranes (Otto-Bruc et al., 1997; Hwang and Koch, 2002), the G2A GCAP1 stimulated the activity of the recombinant RetGC1 expressed in HEK293 cells much less efficiently (Figure 1B).

The dose-dependence of the RetGC activation suggests that the binding of the G2A GCAP1 to its target enzyme is impeded. It needs to be emphasized that GCAP binding to RetGC cannot be measured directly, because detergents required for extraction of RetGC from the membranes inactivate GCAP/RetGC interaction (Koch, 1991; Lambrecht and Koch, 1992). We, therefore, tested GCAP/RetGC complex formation using previously described semi-quantitative analysis of GCAP1-GFP co-localization with RetGC in HEK293 cells (Peshenko et al., 2008) (Figure 2). GCAP1-GFP expressed in the absence of the target enzyme (Figure 2A) distributes in a diffuse pattern throughout the cell, with similar intensity of the fluorescence in the cytoplasm and the nucleus (with the exception of the nucleoli and vacuoles) (Peshenko et al., 2008). The first EF-hand in GCAP1 and GCAP2 does not bind $\mathrm{Ca}^{2+}$, but has been implicated in target recognition/binding instead (Ermilov et al., 2001; Hwang et al., 2004). Therefore, a mutation replacing the conserved CysPro in the EF-hand 1 loop with Gly prevents RetGC stimulation (Hwang et al., 2004). This mutation results in a diffuse pattern of GCAP1GFP, even when it is co-expressed with RetGC1 (Figure 2B). In a sharp contrast, wild type GCAP1-GFP is co-localizes to the membranes containing co-expressed RetGC1 (Figure 2C), thus producing a "tennis racquet" membrane localization pattern specific for GCAP1/RetGC1 binding, as was previously demonstrated (Peshenko et al., 2008, 2011). The G2A GCAP1-GFP co-localization with RetGC1 was generally similar to that of wild type GCAP1, although not as sharply defined as for the wild type (Figure 2D). This indicates that the lack of myristoylation per se does not block RetGC/GCAP interaction, consistently with the activity assay in Figure 1 and the earlier observations by Hwang and Koch (2002) and Dell'Orco et al. (2010). However, a semi-quantitative analysis performed on a large number of cells reveals that the efficiency of the complex formation has been reduced (Figures 2E,F). The quantification analysis is based on the decrease of the fluorescence intensity in the nucleus relative to the cell membranes, caused by absorption of the tagged GCAP1 by RetGC1 expressed in the membranes (Peshenko et al., 2008, 2011). In the absence of RetGC, the ratio of the GCAP1-GFP compartmentalization between the cytoplasm and the nucleus (excluding nucleoli) for average cell is close to 1, but in the presence of RetGC1 it drastically, almost 14-fold (Figure 2), increases 

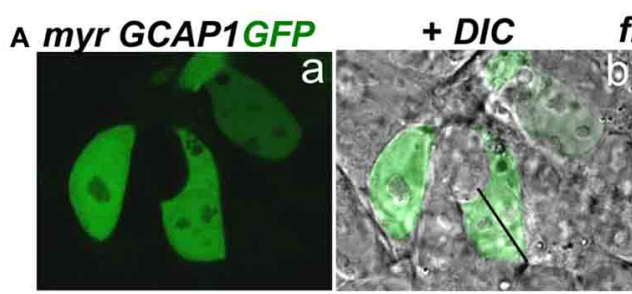

fluorescence profile $\mathrm{B}$
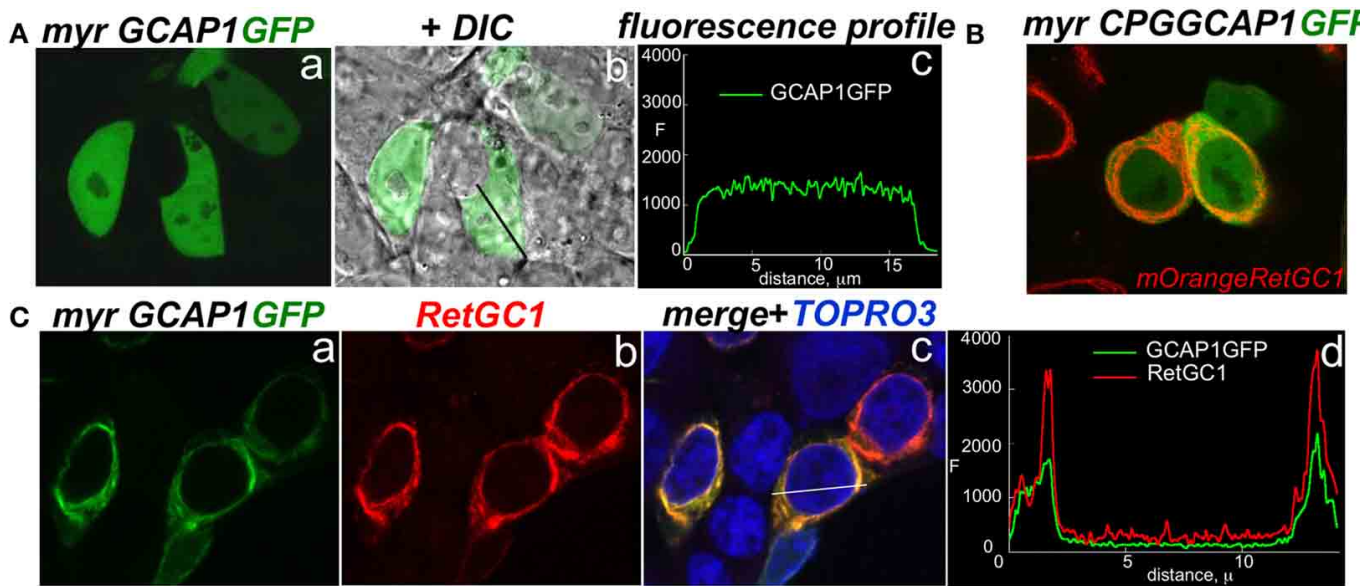

RetGC1
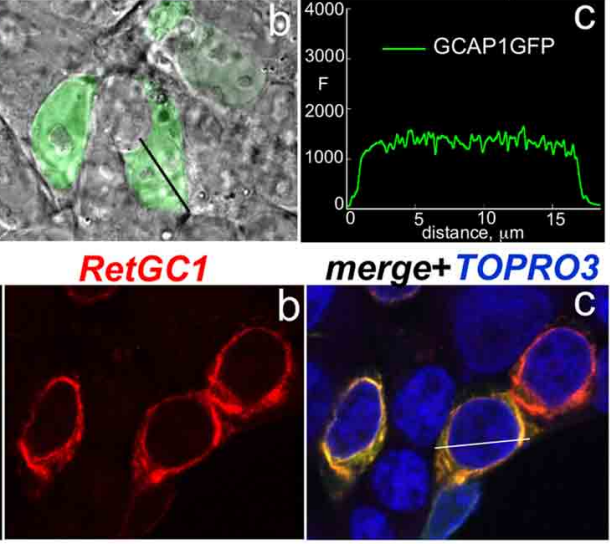

merge+TOPRO3
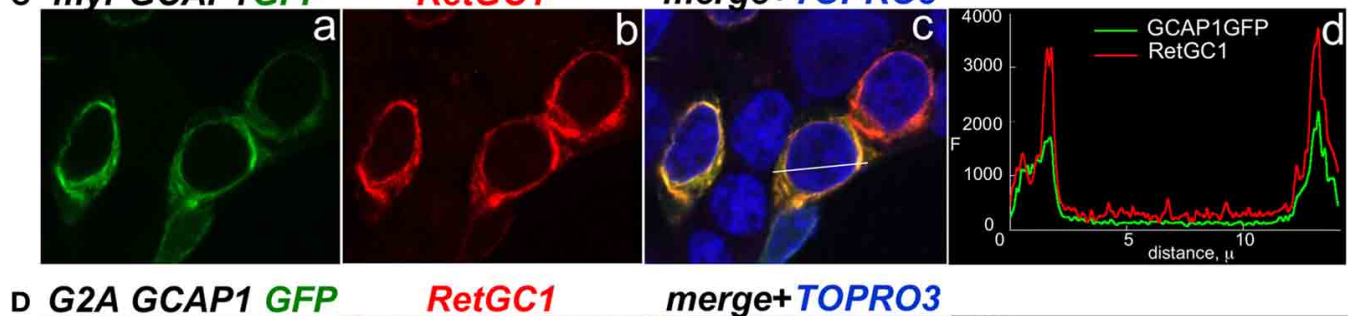

RetGC1
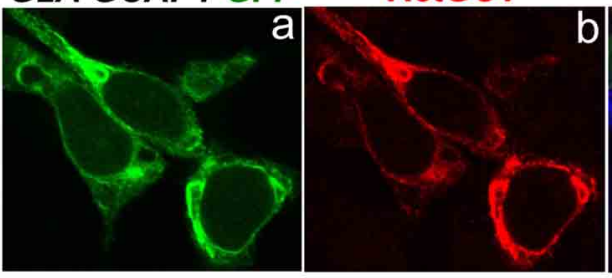

merge+TOPRO3
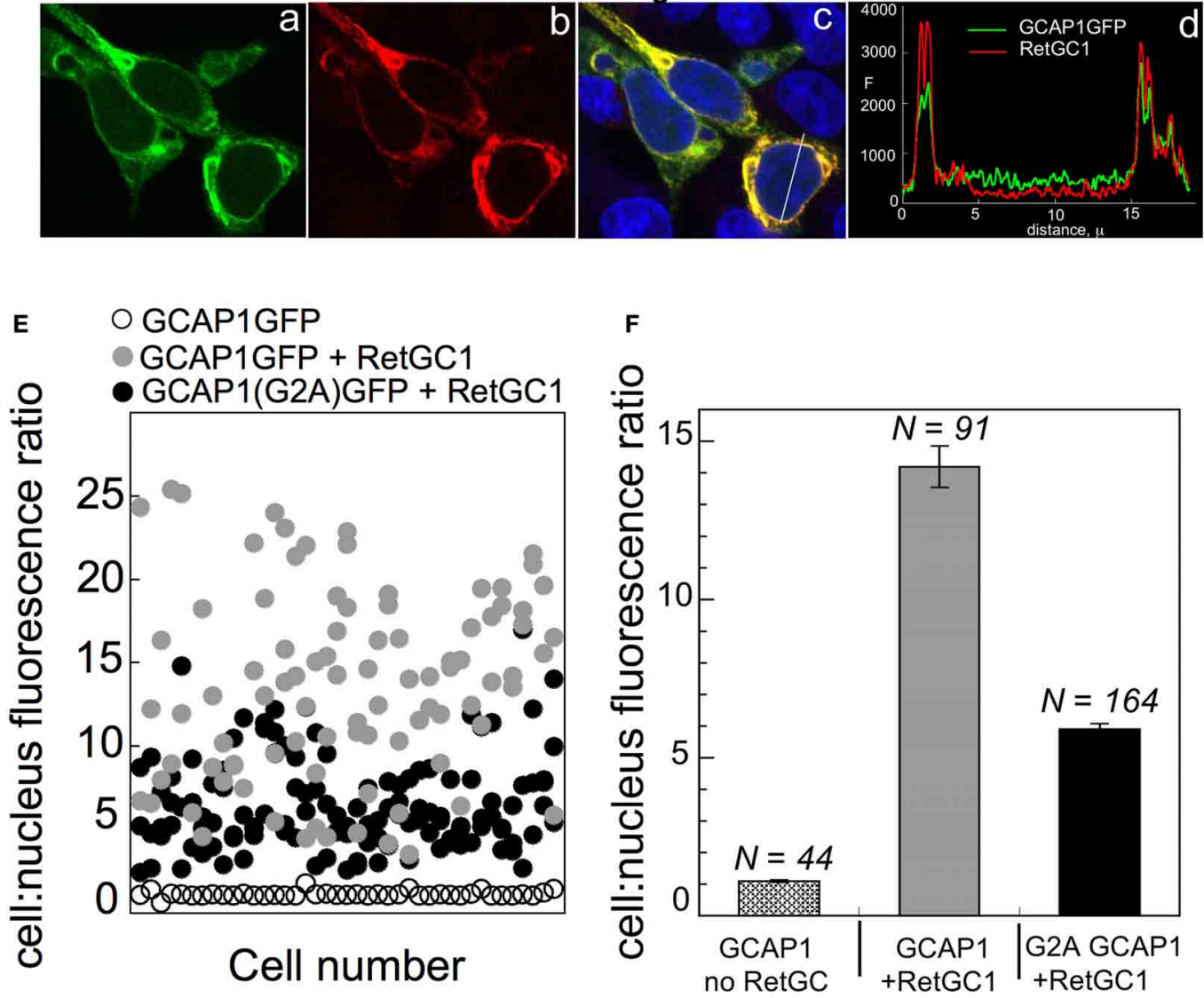

FIGURE 2 | The effect of myristoylation on co-localization of GCAP1 with RetGC in HEK293 cells. (A) GCAP1-GFP expressed in HEK293 cells without RetGC1 produces diffuse pattern spreading over the cytoplasm and the nucleus (Peshenko et al., 2008); a -fluorescence of GCAP1-GFP, b-same, but superimposed on DIC image of the cells, $c$-GCAP1 GFP fluorescence profile recorded across the cell along the black line in "b." (B) GCAP1 GFP mutant, in which a conserved CysPro pair in EF-hand 1 loop required for interaction with RetGC is replaced by Gly (Hwang et al., 2004), was co-expressed with RetGC1 tagged at the $\mathrm{N}$-terminus with mOrange variant of red fluorescent protein using protocol described in (Peshenko et al., 2008, 2011); notice that the diffuse pattern of GCAP1-GFP persists despite the presence of RetGC1. (C) Membrane localization of wild type GCAP1-GFP (green) co-expressed with RetGC1 (red); a-fluorescence of

GCAP1-GFP, $b$-anti-RetGC1 immunofluorescence of AlexaFluor 568, $c$-GCAP1 GFP (green) and anti-RetGC1 (red) fluorescence profile recorded across the cell along the white line shown in " $b$ "; the nuclei in " $c$ " were counterstained with TO-PRO3 (pseudo-blue). (D) Same as C, but using G2A GCAP1-GFP mutant. (E) Distribution of GCAP1-GFP fluorescence between the membranes and the nucleus quantified as described in (Peshenko et al., 2008); each data point corresponds to an individual cell; o-GCAP1-GFP expressed alone, -GCAP1-GFP co-expressed with RetGC1, --G2A GCAP1-GFP co-expressed with RetGC1. (F) The GCAP1-GFP fluorescence distribution ratio (mean \pm SEM) averaged from panel $E$ demonstrates that the G2A GCAP1 mutant compartmentalizes with the RetGC1, although less efficiently than the wild type. 
in favor of the membrane localization (Peshenko et al., 2008). Same analysis for the G2A GCAP1 yields more modest average value of 6-fold. Therefore, although myristoylation is not essential for the RetGC/GCAP binding, it evidently improves the efficiency of the complex formation. At the same time, the lower level of activation of the cyclase in Figure 1B as compared with the less prominently decreased co-localization efficiency in Figure 2F implies that there is additional effect of myristoylation-it has to be involved in the creation of the conformation required for the optimal cyclase stimulation within the GCAP/RetGC complex. It also needs to be noted that the attachment of the C-terminal GFP tag per se does not affect the regulatory properties of GCAP1 as the $\mathrm{Ca}^{2+}$ sensor of guanylyl cyclase (Peshenko et al., 2008).

The effect of N-myristoylation in GCAP1 on the cyclase binding and activation could a priori result from stabilizing effect of the fatty chain buried inside the protein structure (Stephen et al., 2007), such that in the absence of myristoylation GCAP1 becomes more easily misfolded. Previous analysis of the non-acylated GCAP1 by circular dichroism spectra (Dell'Orco et al., 2010) argues that the metal-bound non-myristoylated protein is fairly stable, at least at the level of the secondary structure. On the other hand, the $\mathrm{Ca}^{2+}$ binding isotherms (Dell'Orco et al., 2010) also suggested that at least one of the EF-hands in non-myristoylated GCAP1 became unable to bind $\mathrm{Ca}^{2+}$ within submicromolar $\mathrm{Ca}^{2+}$ range. Hence, one could not rule out the possibility of partial misfolding of GCAP1 three-dimensional structure. However, the data in Figure 3 argue that under the conditions of our experiments the G2A GCAP1 is affected in a very subtle manner that merely results in a slight change of its $\mathrm{Ca}^{2+}$ sensitivity, rather than critical loss of $\mathrm{Ca}^{2+}$ binding affinity in any of the three metal-binding EFhands. The fluorescent indicator dye titration analysis (Peshenko and Dizhoor, 2006) shows that the G2A GCAP1 has a normal stoichiometry of $\mathrm{Ca}^{2+}$ binding-three per molecule, saturating at low micromolar range of free $\mathrm{Ca}^{2+}$ (Figure 3B).

The overall apparent affinity of the G2A GCAP1 for $\mathrm{Ca}^{2+}$ in our experiments (Figure 3B) was markedly better than we could expect for the non-myristoylated GCAP1 based on previous reports. The respective macroscopic equilibrium constants, $K_{1}, K_{2}$, and $K_{3}$, derived from the three-center binding model (Figure 3B) were $2.0 \times 10^{7}, 1.7 \times 10^{7}$, and $3.2 \times 10^{6} \mathrm{M}^{-1}$ for the myristoylated and $1.5 \times 10^{7}, 1.0 \times 10^{7}$, and $2.2 \times 10^{6} \mathrm{M}^{-1}$ for the non-acylated G2A GCAP1. These values substantially deviate from those observed by Dell'Orco et al. (2010) $-2.5 \times 10^{8}$, $3.2 \times 10^{7}$, and $7.9 \times 10^{7} \mathrm{M}^{-1}$ for myristoylated versus $6.3 \times 10^{7}$, $5.0 \times 10^{6}$, and $2.0 \times 10^{3} \mathrm{M}^{-1}$ for non-myristoylated GCAP1. The binding isotherm in our study (solid line) looks substantially different from the isotherm "reconstituted" using the previously reported (Dell'Orco et al., 2010) constants (dashed line)-both reach the same binding stoichiometry, but in very different free $\mathrm{Ca}^{2+}$ range. Based on our results, we can positively state that not only the stoichiometry of $\mathrm{Ca}^{2+}$ binding does not change in the non-myristoylated GCAP1, but it also reaches saturation within nearly the same low micromolar range as myristoylated protein, with only a slight right-shift of the binding curve (Figures 3A,B). It needs to be mentioned that indirect evaluation of $\mathrm{Ca}^{2+}$ binding affinities was also performed previously using a complex microcalorimetric pattern of heat release by GCAP1 in response to $\mathrm{Ca} 2+$ binding ( $\mathrm{Lim}$ et al., 2009). However, using the $\mathrm{Ca}^{2+}$ binding isotherm (such as in Peshenko and Dizhoor (2006) and this study) is a more reliable approach to determine the actual binding constants, because, unlike microcalorimetry, it is not affected by a complex relationship between heat release and absorption resulting from $\mathrm{Ca}^{2+}$ binding and conformational changes in the GCAP1 molecule (Lim et al., 2009).

To verify that our analysis did not simply fail to reveal a major difference between the two forms of GCAP1 due to an insufficient resolution of the $\mathrm{Ca}^{2+}$ binding assay, we also tested $\mathrm{Ca}^{2+}$ binding by non-acylated GCAP1 mutants in which we inactivated one (EF-4) or two (EF-3 and EF-4) EF-hands using the D144N/D148G (EF4 ${ }^{-}$) and the D100N/D102G/D144N/D148G $\left(\mathrm{EF} 3,4^{-}\right)$substitutions, respectively, (Peshenko and Dizhoor, 2006). In both cases, we clearly observed the corresponding decrease of $\mathrm{Ca}^{2+}$ binding by one (Figure 3C) or two (Figure 3D) mol $\mathrm{Ca}^{2+}$ per mol GCAP1, respectively. So we find no indications that any of the three metal binding EF-hands in the non-acylated GCAP1 undergo possible misfolding severely affecting binding of $\mathrm{Ca}^{2+}$. Therefore, the general fold of GCAP1 is highly unlikely to be critically compromised by the absence of the myristoyl group. It is much more likely that the fatty acyl group changes GCAP1 structure in a fairly subtle manner, only slightly affecting $\mathrm{Ca}^{2+}$ binding within the physiological free $\mathrm{Ca}^{2+}$ range.

The reason for the difference in the $\mathrm{Ca}^{2+}$ binding affinities in our study and that by Dell'Orco et al. (2010) is not immediately apparent. The trace amount of EDTA $(\sim 1: 20$ molar ratio to GCAP1, or 1:60 per mol of $\mathrm{Ca}^{2+}$ binding sites) was negligible in our assays and could not skew the results by more than few percent [which also would be toward lower, contrary to the higher than in Dell'Orco et al. (2010), average affinity in our experiments (Figure 3B)]. In the method we use (Peshenko and Dizhoor, 2006), the fluorescent chelator indicator was also present at a very low $(\sim 1: 60-1: 40)$ molar ratio to GCAP1 (as low as 1:180-1:120 per mol of $\mathrm{Ca}^{2+}$ binding sites), quite negligible in comparison with the calcium buffer capacity of GCAP1 itself and $~ 40-60$ times lower than in the method used by Dell'Orco et al. (2010). This may have prevented some potential effect of the chelator dye itself on the non-myristoylated protein. Alternatively, the difference could be related to the use of the protein purification protocol that more efficiently removes poorly folded fraction of low-affinity GCAP1 in our study.

Despite the substantial quantitative difference, we would nonetheless emphasize that we have a qualitative agreement with the findings by Dell'Orco et al. (2010) - $\mathrm{Ca}^{2+}$-sensitivity of the G2A GCAP1 is reduced compared to the myristoylated form (Figure 3A). Even though the binding ratio at saturation remained three $\mathrm{Ca}^{2+}$ ions per GCAP1, there was a slight shift of the curve toward higher micromolar free $\mathrm{Ca}^{2+}$ range for the nonmyristoylated GCAP1. Evidently, it is the lack of myristoylation what alters the properties of GCAP1, not the G2A mutation per se (Figure 3A).

From the overall shift in $\mathrm{Ca}^{2+}$ binding affinity in non-acylated GCAP1 (Figure 3A), the result shown in Figure 3D appears most intriguing. The affinity of EF-hand 2, the only metal-binding site left in the non-acylated D100N/D102G/D144N/D148G GCAP1 

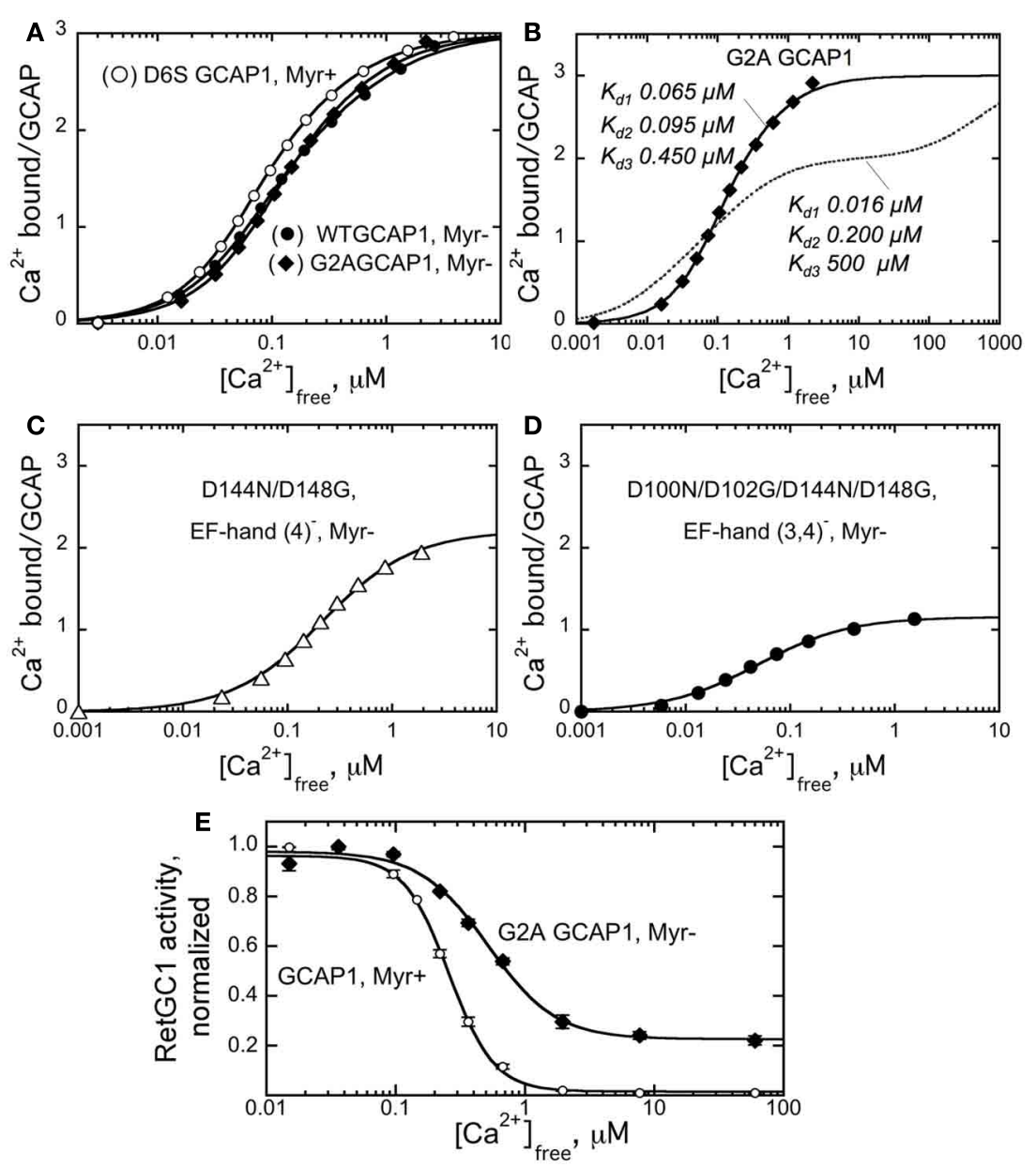

FIGURE $3 \mid \mathrm{Ca}^{2+}$ sensitivity of GCAP1 is affected by myristoylation. (A-D), $\mathrm{Ca}^{2+}$ binding isotherms obtained using fluorescent indicator dye BAPTA-2 titration protocol (Peshenko and Dizhoor, 2006). (A) $\mathrm{Ca}^{2+}$ binding by myristoylated D6S GCAP1 (o), non-myristoylated WT GCAP1 (•), and non-myristoylated G2A GCAP1 ( $)$. (B) Comparison of the experimental data for $\mathrm{Ca}^{2+}$ binding by G2A GCAP1 ( $)$ with the theoretical curve for three-center binding model calculated using previously reported macroscopic association constants, $6.3 \times 10^{7}, 5.0 \times 10^{6}$, and $2.0 \times 10^{3} \mathrm{M}^{-1}$ (Dell'Orco et al., 2010) (- - -); the corresponding dissociation constants are shown next to each trace. (C,D) Change of the binding stoichiometry in non-myristoylated GCAP1 with one (D144N/D148G, C) or two (D100N/D102G/D144N/D148G, D) EF-hands inactivated. The data were fitted using two different models: panels $(\mathbf{A}, \mathbf{B})$-by three-center binding model, $\mathrm{Ca}_{\text {bound }} / \mathrm{GCAP}=\left(K_{1} \mathrm{Ca}_{f}+2 K_{1} K_{2} \mathrm{Ca}_{f}^{2}+3 K_{1} K_{2} K_{3} \mathrm{Ca}_{f}^{3}\right) /\left(1+K_{1} \mathrm{Ca}_{f}+\right.$ $\left.K_{1} K_{2} \mathrm{Ca}_{f}^{2}+K_{1} K_{2} K_{3} \mathrm{Ca}_{f}^{3}\right)$, where $K_{1}, K_{2}$, and $K_{3}$ are macroscopic equilibrium constants; panels (C,D) - by simplified hyperbolic saturation function, $\left(\mathrm{Ca}_{\text {bound }} / \mathrm{GCAP}\right)=B_{\max } \times \mathrm{Ca}_{\text {free }} /\left(\mathrm{Ca}_{\text {free }}+K_{d}\right)$, where $\mathrm{Ca}_{\text {bound }}$ is the concentration of $\mathrm{Ca}^{2+}$ bound to GCAP1, calculated as $\mathrm{Ca}_{\text {bound }}=\mathrm{Ca}_{\text {total }}-$ Cafree, $B_{\text {max }}$ is mol of $\mathrm{Ca}^{2+}$ bound per mol of GCAP1 at saturation, $K_{d}$ is the apparent dissociation constant. The data shown are representative from 3 to 5 independent experiments producing virtually identical results. (E) Normalized activity of the recombinant RetGC1 expressed in HEK293 cells reconstituted with $10 \mu \mathrm{M}$ purified myristoylated GCAP1 (o) or G2A GCAP1 (•) at different free $\mathrm{Ca}^{2+}$ concentrations and $1 \mathrm{~mm}$ free $\mathrm{Mg}^{2+}$. The activities in each series were normalized by the maximal activity in the corresponding series. The data were fitted by the equation,

$A=A_{\max }+\left(A_{\max }-A_{\min }\right) /\left(1+\left(\mathrm{Ca}_{\text {free }} / \mathrm{Ca}_{1 / 2}\right)^{n}\right)$, where $A$ is RetGC activity, $\mathrm{Ca}_{1 / 2}$ is the free $\mathrm{Ca}^{2+}$ concentration producing $50 \%$ effect and $n$ is the Hill coefficient. For other conditions of the assay see Materials and Methods. mutant (Figure 3D), remains high $\left(K_{d} \sim 0.04 \mu \mathrm{m} \pm 0.01\right)$, virtually the same as in the myristoylated D100N/D102G/D144N/ D148G mutant [0.03 $\pm 0.01 \mu \mathrm{m}$, Peshenko and Dizhoor (2006)]. In other words, myristoylation appears to have a surprisingly little effect on the high-affinity $\mathrm{Ca}^{2+}$ binding in the EF-hand 2 proximal to the fatty acyl group in the three-dimensional structure of GCAP1 (Figure 1). Instead of affecting metal binding in the neighboring EF-hand 2, the myristoyl moiety, in a rather paradoxical manner, seemingly influences the efficiency of $\mathrm{Ca}^{2+}$ binding in a more distal portion of the molecule (EF-hand 3 or 4 ).
In our previous studies (Peshenko and Dizhoor, 2007; Peshenko et al., 2008), we identified the EF-hand 3/EF-hand 4 portion of the molecule as critical for the $\mathrm{Ca}^{2+}$-dependent activator-to-inhibitor transition of GCAP1. In a good qualitative agreement with the earlier observations of Hwang and Koch (2002) and the shift in the $\mathrm{Ca}^{2+}$-binding isotherm to the higher $\mathrm{Ca}^{2+}$ range (Figure 3A), the G2A GCAP1 regulated recombinant RetGC1 with a noticeably lower sensitivity to $\mathrm{Ca}^{2+}\left[(\mathrm{Ca})_{1 / 2}\right.$ increased from $260 \mathrm{nM}$ in wild type to $520 \mathrm{nM}$ in the G2A mutant (Figure 3E)]. Since the high-affinity binding in EF-hand 2 does 
not seem to be critically affected by myristoylation (Figure 3D), the observed changes in $\mathrm{Ca}^{2+}$ sensitivity of RetGC1 (Figure 3E) are, again, likely attributable to the change in the function of EFhand 3 and/or 4 . It also needs to be pointed that even though the decrease in $\mathrm{Ca}^{2+}$ sensitivity of RetGC regulation by GCAP1 is relatively modest, $\sim 2$-fold, a shift like this can be large enough to adversely affect the levels of free cGMP and $\mathrm{Ca}^{2+}$ in the dark and provoke photoreceptor death in transgenic mice (Olshevskaya et al., 2004; Woodruff et al., 2007). Therefore, the role of myristoylation in maintaining normal $\mathrm{Ca}^{2+}$ sensitivity of GCAP1 as a $\mathrm{Ca}^{2+}$ sensor should be rather important for its normal physiological function.

Our results indicate that myristoyl residue inside the GCAP1 molecule affects proximal structural element(s) involved in the target enzyme recognition, such as EF-1 (see Ermilov et al., 2001;

\section{REFERENCES}

Ames, J. B., Dizhoor, A. M., Ikura, M., Palczewski, K., and Stryer, L. (1999). Three-dimensional structure of guanylyl cyclase activating protein-2, a calcium-sensitive modulator of photoreceptor guanylyl cyclases. J. Biol. Chem. 274, 19329-19337.

Ames, J. B., Ishimam, R., Tanaka, T., Gordon, J. I., Stryer, L., and Ikura, M. (1997). Molecular mechanics of calcium-myristoyl switches. Nature 389, 198-202.

Ames, J. B., Tanaka, T., Ikura, M., and Stryer, L. (1995). Nuclear magnetic resonance evidence for $\mathrm{Ca}(2+)$ induced extrusion of the myristoyl group of recoverin. J. Biol. Chem. 270, 30909-30913.

Burgoyne, R. D. (2007). Neuronal calcium sensor proteins, generating diversity in neuronal $\mathrm{Ca} 2+$ signalling. Nat. Rev. Neurosci. 8, 182-193.

Burns, M. E., Mendez, A., Chen, J., and Baylor, D. A. (2002). Dynamics of cyclic GMP synthesis in retinal rods. Neuron 36, 81-91.

Dell'Orco, D., Behnen, P., Linse, S., and Koch, K. W. (2010). Calcium binding, structural stability and guanylate cyclase activation in GCAP1 variants associated with human cone dystrophy. Cell. Mol. Life Sci. 67, 973-984

Dizhoor, A. M., Boikov, S. G., and Olshevskaya, E. V. (1998). Constitutive activation of photoreceptor guanylate cyclase by Y99C mutant of GCAP-1. Possible role in causing human autosomal dominant cone degeneration. J. Biol. Chem. 273, 17311-17314.

Dizhoor, A. M., Chen, C. K., Olshevskaya, E. V., Sinelnikova, V., Phillipov, P., and Hurley, J. B. (1993). Role of the acylated amino terminus of recoverin in $\mathrm{Ca}(2+)$ dependent membrane interaction. Science 259, 829-832.

Dizhoor, A. M., Ericsson, L. H., Johnson, R. S., Kumar, S., Olshevskaya, E. V., Zozulya, S., Neubert, T. A., Stryer, L., Hurley, J. B., and Walsh, K. A. (1992). The $\mathrm{NH} 2$ terminus of retinal recoverin is acylated by a small family of fatty acids. J. Biol. Chem. 267, 16033-16036.

Dizhoor, A. M., and Hurley, J. B. (1996). Inactivation of EF-hands makes GCAP-2 (p24) a constitutive activator of photoreceptor guanylyl cyclase by preventing a $\mathrm{Ca} 2+-$ induced "activator-to-inhibitor" transition. J. Biol. Chem. 271, 19346-19350.

Dizhoor, A. M., Lowe, D. G., Olshevskaya, E. V., Laura, R. P., and Hurley, J. B. (1994). The human photoreceptor membrane guanylyl cyclase, RetGC, is present in outer segments and is regulated by calcium and a soluble activator. Neuron 12, 1345-1352.

Dizhoor, A. M., Olshevskaya, E. V., Henzel, W. J., Wong, S. C., Stults, J. T., Ankoudinova, I., and Hurley, J. B. (1995). Cloning, sequencing, and expression of a $24-\mathrm{kDa}$ $\mathrm{Ca}(2+)$-binding protein activating photoreceptor guanylyl cyclase. J. Biol. Chem. 270, 25200-25206.

Dizhoor, A. M., Olshevskaya, E. V., and Peshenko, I. V. (2010). Mg2+/Ca2+ cation binding cycle of guanylyl cyclase activating proteins (GCAPs), role in regulation of photoreceptor guanylyl cyclase. Mol. Cell. Biochem. 334, 117-124.

Ermilov, A. N., Olshevskaya, E. V., and Dizhoor, A. M. (2001). Instead of binding calcium, one of the EF-hand structures in guanylyl cyclase activating protein-2 is

Hwang et al., 2004), but also influences $\mathrm{Ca}^{2+}$ binding efficacy in a more distal part of the molecule through a presently unknown and somewhat paradoxical mechanism. The possibility that the intramolecular interactions exist between the myristoyl moiety and the remote portions of the GCAP1 structure also suggests that such interaction can be affected by the environment of the myristoyl group and deserves closer in-depth study. This study is currently in progress and could provide a new insight into the structure-function relationships underlying the $\mathrm{Ca}^{2+}$ sensor action of GCAP1 as a member of the NCS protein group.

\section{ACKNOWLEDGMENTS}

This work was supported by the NIH grant EY11522 from NEI. Alexander M. Dizhoor is the Martin and Florence Hafter Chair Professor of Pharmacology.

required for targeting photoreceptor guanylyl cyclase. J. Biol. Chem. 276, 48143-48148.

Fu, Y., and Yau, K. W. (2007). Phototransduction in mouse rods and cones. Pflugers Arch. 454 805-819.

Gorczyca, W. A., Gray-Keller, M. P., Detwiler, P. B., and Palczewski, K. (1994). Purification and physiological evaluation of a guanylate cyclase activating protein from retinal rods. Proc. Natl. Acad. Sci. U.S.A. 91, 4014-4018.

Gray-Keller, M. P., and Detwiler, P. B. (1994). The calcium feedback signal in the phototransduction cascade of vertebrate rods. Neuron 13, 849-861.

Hughes, R. E., Brzovic, P. S., Dizhoor, A. M., Klevit, R. E., and Hurley, J. B. (1998). Ca2+-dependent conformational changes in bovine GCAP-2. Protein Sci. 7, 2675-2680.

Hwang, J. Y., and Koch, K. W. (2002). Calcium- and myristoyl-dependent properties of guanylate cyclaseactivating protein-1 and protein-2. Biochemistry 41, 13021-13028.

Hwang, J. Y., Lange, C., Helten, A., Hoppner-Heitmann, D., Duda, T., Sharma, R. K., and Koch, K. W. (2003). Regulatory modes of rod outer segment membrane guanylate cyclase differ in catalytic efficiency and Ca2+-sensitivity. Eur. J. Biochem. 270, 3814-3821.

Hwang, J. Y., Schlesinger, R., and Koch, K. W. (2004). Irregular dimerization of guanylate cyclase-activating protein 1 mutants causes loss of target activation. Eur. J. Biochem. 271, 3785-3793.

Imanishi, Y., Yang, L., Sokal, I., Filipek, S., Palczewski, K., and Baehr, W. (2004). Diversity of guanylate cyclase-activating proteins (GCAPs) in teleost fish, characterization of three novel GCAPs (GCAP4, GCAP5, GCAP7) from zebrafish (Danio rerio) and prediction of eight GCAPs (GCAP1-8) in pufferfish (Fugu rubripes). J. Mol. Evol. 59, 204-217.

Johnson, R. S., Ohguro, H., Palczewski, K., Hurley, J. B., Walsh, K. A., and Neubert, T. A. (1994). Heterogeneous $\mathrm{N}$-acylation is a tissue- and species-specific posttranslational modification. J. Biol. Chem. 269, 21067-21071.

Koch, K. W. (1991). Purification and identification of photoreceptor guanylate cyclase. J. Biol. Chem. 266, 8634-8637.

Koch, K. W., and Stryer, L. (1988). Highly cooperative feedback control of retinal rod guanylate cyclase by calcium ions. Nature 334, 64-66.

Krylov, D. M., Niemi, G. A., Dizhoor, A. M., and Hurley, J. B. (1999). Mapping sites in guanylyl cyclase activating protein-1 required for regulation of photoreceptor membrane guanylyl cyclases. J. Biol. Chem. 274, 10833-10839.

Laura, R. P., Dizhoor, A. M., and Hurley, J. B. (1996). The membrane guanylyl cyclase, retinal guanylyl cyclase-1, is activated through its intracellular domain. J. Biol. Chem. 271, 11646-11651.

Lim, S., Peshenko, I., Dizhoor, A., and Ames, J. B. (2009). Effects of $\mathrm{Ca} 2+, \mathrm{Mg}_{2}+$, and myristoylation on guanylyl cyclase activating protein 1 structure and stability. Biochemistry 48, 850-862.

Lim, S., Strahl, T., Thorner, J., and Ames, J. B. (2011). Structure of a Ca2+-myristoyl switch protein that controls activation of a phosphatidylinositol 4-kinase in fission yeast. J. Biol. Chem. 286, 12565-12577. 
Lambrecht, H. G., and Koch, K. W. (1992). Recoverin, a novel calciumbinding protein from vertebrate photoreceptors. Biochim. Biophys. Acta 1160, 63-66.

Makino, C. L., Peshenko, I. V., Wen, X.-H., Elena, V., Olshevskaya, E. V., Barrett, R., and Dizhoor, A. M. (2008). A role for GCAP2 in regulating the photoresponse: guanylyl cyclase activation and rod electrophysiology in GUCA1B knockout mice. J. Biol. Chem. 283, 29135-29143.

Mendez, A., Burns, M. E., Sokal, I., Dizhoor, A. M., Baehr, W., Palczewski, K., Baylor, D. A., and Chen, J. (2001). Role of guanylate cyclase-activating proteins (GCAPs) in setting the flash sensitivity of rod photoreceptors. Proc. Natl. Acad. Sci. U.S.A. 98, 9948-9953.

Olshevskaya, E. V., Calvert, P. D., Woodruff, M. L., Peshenko, I. V., Savchenko, A. B., Makino, C. L., Ho, Y. S., Fain, G. L., and Dizhoor, A. M. (2004). The Y99C mutation in guanylyl cyclase-activating protein 1 increases intracellular $\mathrm{Ca} 2+$ and causes photoreceptor degeneration in transgenic mice. J. Neurosci. 24, 6078-6085.

Olshevskaya, E. V., Hughes, R. E., Hurley, J. B., and Dizhoor, A. M. (1997). Calcium binding, but not a calcium-myristoyl switch, controls the ability of guanylyl cyclase-activating protein GCAP-2 to regulate photoreceptor guanylyl cyclase. J. Biol. Chem. 272, 14327-14333.

Otto-Bruc, A., Buczylko, J., Surgucheva, I., Subbaraya, I., Rudnicka-Nawrot, M., Crabb, J. W., Arendt, A., Hargrave, P. A., Baehr, W., and Palczewski, K. (1997). Functional reconstitution of photoreceptor guanylate cyclase with native and mutant forms of guanylate cyclase-activating protein 1. Biochemistry 36, 4295-4302.
Palczewski, K., Subbaraya, I., Gorczyca, W. A., Helekar, B. S., Ruiz, C. C., Ohguro, H., Huang, J., Zhao, X., Crabb, J. W., Johnson, R. S., Walsh, K. A., Gray-Keller, M. P., Detwiller, P. B., and Baehr, W. (1994). Molecular cloning and characterization of retinal photoreceptor guanylyl cyclaseactivating protein. Neuron 13, 395-404.

Peshenko, I. V., and Dizhoor, A. M. (2004). Guanylyl cyclase-activating proteins (GCAPs) are $\mathrm{Ca} 2+/ \mathrm{Mg} 2+$ sensors: implications for photoreceptor guanylyl cyclase (RetGC) regulation in mammalian photoreceptors. J. Biol. Chem. 279, 16903-16906.

Peshenko, I. V., and Dizhoor, A. M. (2006). Ca2+ and $\mathrm{Mg} 2+$ binding properties of GCAP-1. Evidence that Mg2+-bound form is the physiological activator of photoreceptor guanylyl cyclase. J. Biol. Chem. 281, 23830-23841.

Peshenko, I. V., and Dizhoor, A. M. (2007). Activation and inhibition of photoreceptor guanylyl cyclase by guanylyl cyclase activating protein 1 (GCAP-1): the functional role of $\mathrm{Mg} 2+/ \mathrm{Ca} 2+$ exchange in EF-hand domains. J. Biol. Chem. 282, 21645-21652. Epub 22007 Jun 21641.

Peshenko, I. V., Moiseyev, G. P., Olshevskaya, E. V., and Dizhoor, A. M. (2004). Factors that determine $\mathrm{Ca} 2+$ sensitivity of photoreceptor guanylyl cyclase. Kinetic analysis of the interaction between the $\mathrm{Ca} 2+$-bound and the $\mathrm{Ca} 2+$-free guanylyl cyclase activating proteins (GCAPs) and recombinant photoreceptor guanylyl cyclase 1 (RetGC-1). Biochemistry 43, 13796-13804.

Peshenko, I. V., Olshevskaya, E. V., and Dizhoor, A. M. (2008). Binding of guanylyl cyclase activating protein 1 (GCAP1) to retinal guanylyl cyclase (RetGC1). The role of individual
EF-hands. J. Biol. Chem. 283, 21747-21757.

Peshenko, I. V., Olshevskaya, E. V., Savchenko, A. B., Karan, S., Palczewski, K., Baehr, W., and Dizhoor, A. M. (2011). Enzymatic properties and regulation of the native isozymes of retinal membrane guanylyl cyclase (RetGC) from mouse photoreceptors. Biochemistry 50, 5590-5600.

Peshenko, I. V., Olshevskaya, E. V., Yao S., Ezzeldin, H. H., Pittler, S. J., and Dizhoor, A. M. (2010). Activation of retinal guanylyl cyclase RetGC1 by GCAP1: stoichiometry of binding and effect of new LCA-related mutations. Biochemistry 49, 709-717.

Pugh, E. N. Jr., Duda, T., Sitaramayya, A., and Sharma, R. K. (1997). Photoreceptor guanylate cyclases: a review. Biosci. Rep. 17, 429-473.

Pugh, E. N. Jr., Nikonov, S., and Lamb, T. D. (1999). Molecular mechanisms of vertebrate photoreceptor light adaptation. Curr. Opin. Neurobiol. 9 , 410-418.

Sakurai, K., Chen, J., and Kefalov, V. J. (2011). Role of guanylyl cyclase modulation in mouse cone phototransduction. J. Neurosci. 31, 7991-8000.

Sampath, A. P., Matthews, H. R. Cornwall, M. C., Bandarchi, J., and Fain, G. L. (1999). Light-dependent changes in outer segment free-Ca2+ concentration in salamander cone photoreceptors. J. Gen. Physiol. 113 , 267-277.

Stephen, R., Bereta, G., Golczak, M. Palczewski, K., and Sousa, M. C. (2007). Stabilizing function for myristoyl group revealed by the crystal structure of a neuronal calcium sensor, guanylate cyclase-activating protein 1. Structure 15, 1392-1402. Stephen, R., Palczewski, K., and Sousa, M. C. (2006). The crystal structure of GCAP3 suggests molecular mechanism of GCAP-linked cone dystrophies. J. Mol. Biol. 359, 266-275.
Tsien, R., and Pozzan, T. (1989). Measurement of cytosolic free Ca2+ with quin2. Methods Enzymol. 172, 230-262.

Woodruff, M. L., Olshevskaya, E. V., Savchenko, A. B., Peshenko, I. V., Barrett, R., Bush, R. A., Sieving, P. A., Fain, G. L., and Dizhoor, A. M. (2007). Constitutive excitation by Gly90Asp rhodopsin rescues rods from degeneration caused by elevated production of cGMP in the dark. J. Neurosci. 27, 8805-8815.

Woodruff, M. L., Sampath, A. P., Matthews, H. R., Krasnoperova, N. V., Lem, J., and Fain, G. L. (2002). Measurement of cytoplasmic calcium concentration in the rods of wild-type and transducin knockout mice. J. Physiol. 542, 843-854.

Zozulya, S., and Stryer, L. (1992). Calcium-myristoyl protein switch. Proc. Natl. Acad. Sci. U.S.A. 89, 11569-11573.

Conflict of Interest Statement: The authors declare that the research was conducted in the absence of any commercial or financial relationships that could be construed as a potential conflict of interest.

Received: 09 January 2012; accepted: 09 February 2012; published online: 22 February 2012.

Citation: Peshenko IV, Olshevskaya EV and Dizhoor AM (2012) Interaction of GCAP1 with retinal guanylyl cyclase and calcium: sensitivity to fatty acylation. Front. Mol. Neurosci. 5:19. doi: 10.3389/ fnmol.2012.00019

Copyright () 2012 Peshenko, Olshevskaya and Dizhoor. This is an open-access article distributed under the terms of the Creative Commons Attribution Non Commercial License, which permits non-commercial use, distribution, and reproduction in other forums, provided the original authors and source are credited. 